\title{
Flash Flood Hazard Mapping Using Satellite Images and GIS Tools: A case study of the central High Atlas (Morocco).
}

\author{
F. El Bchari ${ }^{\mathrm{a}} *$, B. Theilen-Willige ${ }^{\mathrm{b}}$ and A. Souhel ${ }^{\mathrm{c}}$ \\ ${ }^{a}$ Department of Earth Science, Polydisciplinary Faculty-University of Cadi Ayyad, Safi, Morocco, elbchari@yahoo.fr \\ ${ }^{b}$ Institute of Applied Geosciences, Technical University, Berlin, Germany \\ ${ }^{c}$ Department of Earth Science, Faculty of Sciences- University of Chouaib Doukkali, El Jadida Morocco. \\ * Corresponding author
}

Keywords: Flood hazard zonation map, geoinformation system (GIS), satellite image, Central High Atlas, Morocco

\begin{abstract}
:
Flash flood is generally defined as a rapid onset of flood with a short duration and a relatively high peak discharge. It occurs rapidly, generally within one hour of rainfall, and sometimes accompanied by landslides, mud flows, bridge collapse, damage to buildings, and fatalities (Hapuarachchi et al., 2011).

They cause extensive disruptions to a diverse range of living, working, societal, and spatial environments, the raison why they are reported to be one of the deadliest and most expensive natural hazards worldwide.

Flood damages do not only depend on precipitation amounts but are also a consequence of geomorphological factors and human influences (Maruša et al., 2014) and in this study, the main attention is particularly concentrated on geomorphological factors to flooding. Flash flood events can be characterized by the amount of rain responsible to their occurrences and their duration.

Leaving aside droughts, floods are one of the most dangerous meteorological hazards in Morocco, followed by wind/sandstorms, with the largest frequency of occurrence and the largest number of victims (EM-Dat. 2014). Heavy rains often induce floods in Morocco, including flash floods, riverine floods and mud floods during the rainy season (TheilenWillige, B. 2015). For example, in 2014, The violent storms of 22-30 November 2014, resulted in flash floods and rivers floods in large parts of Southern Morocco. The Guelmim area was the most affected part with at least 32 fatalities and important infrastructure damages. In August 2015 Heavy rain $(299 \mathrm{~m})$ causes flooding in some area parts of the Geoparc of Mgoun (central High Atlas, Moroco): such as Tllouguit, Zawiat Ahancal,and Ait Bou Guemmez Indeed, this episode affected regional roads, bridges, schools and agricutural infrastractures, water supply and electrical networks and caused several people homeless, 3 deaths and important infrastructure damages.

The torrential rains caused flooding of Ahancal and Bou Gemmez river and submerging roads and bridges.

This flooding event rose the question of whether and how remote sensing and GIS tools could be used in an effective manner in order to contribute to a better understanding of the factors leading to this flooding hazard and how to mitigate damage in future by providing maps of areas that have been flooded in the past and areas that are susceptible to flooding due to their morphologic settings during extreme precipitation events.

The flooding hazard in the High atlas of Azilal region initiated this study in order to investigate the use of remote sensing and geographic information system (GIS) for the detection and identification of areas most likely to be flooded in the future again due to their morphologic properties during similar weather conditions. By combining morphometric analysis of the investigation area involving the quantitative analysis of the landforms based on Digital Elevation Model (DEM) data (Aster GDEM, SRTM-DEM, ALOS PALSAR-DEM) and visual interpretation based on satellite image. The resulting maps of weighted overlay procedures, aggregating causal, morphometric factors influencing the susceptibility to flooding (lowest height levels, flattest areas), allowed for the distinguishing of areas with higher, medium and lower susceptibility to flooding. Thus, GIS and remote sensing tools contribute to the recognition and mapping of areas and infrastructure prone to flooding in this area.

Satellite radar data as Sentinel 1, A and B, with acquisition times at or near the flooding events help to identify flooded areas due to the typical mirror-like radar signal reflection of water bodies. Optical satellite data (Sentinel 2, Landsat 8) (often useless during the flooding events because of the cloud cover) taken after flooding events can be used to monitor the traces of flash floods such as sediment accumulation areas or erosional features. Merging this information with infrastructural data in a GIS environment contributes to the detection of flooding hazard prone areas and, thus, to hazard preparedness.
\end{abstract}

